\title{
Aggression and Violent Behaviour: A Critical Review
}

\author{
Th. Bihari Singh ${ }^{1}$, Rakesh Mohanty ${ }^{2}$, Lalrhiatpuia ${ }^{2}$, Mary Haobam ${ }^{3}$, \\ Mohit Saini ${ }^{2}$ \\ ${ }^{I}$ Associate Professor, Dept of Psychiatry, \\ ${ }^{2}$ Post Graduate Student, Dept of Psychiatry, Regional Institute Of Medical Sciences, Imphal, \\ ${ }^{3}$ Member Secretary, Manipur State Mental Health Authority.
}

\begin{abstract}
Aggression is a response by an individual that delivers something unpleasant to another person. Violence refers to extreme forms of aggression, such as physical assault and murder. Even if male preponderance is there aggression is also common in females. This review article provides a brief knowledge about the various factors responsible for aggression and violence. The main focus of the article is to intervene successfully in aggression and violent behaviour. Overall, it is concluded that there is sufficient evidence currently available to substantiate the claim that personal violence can be reduced by psychosocial interventions, but that much more research is required to delineate the parameters of effectiveness in this context. Prevention at family level, community level and in school level will reduce the occurrence of aggression and violence significantly.
\end{abstract}

Keywords: Aggression; Violence; Intervene; Psychosocial.

\section{Introduction}

By definitions, aggression is a response by an individual that delivers something unpleasant to another person ${ }^{[1]}$. Aggression can take a variety of forms which may be expressed physically or communicated verbally or non-verbally. Violence refers to extreme forms of aggression, such as physical assault and murder ${ }^{[1]}$. Beaver et al 2014 argues that human aggression might have evolved as a way of, for instance, negotiating status and power hierarchies, discouraging aggressive behavior from rivals, and discouraging mates from sexual infidelity ${ }^{[2]}$.

\section{Gender}

Although there is much variation in species, generally the more physically aggressive sex is the male, particularly in mammals. This perception was challenged when social psychologists began to study non-overt forms of aggression ${ }^{[3]}$. This later work found striking sex differences in aggression types, at least in children and adolescents. Boys typically engage in aggression that involves a direct physical and/or verbal assault (i.e., hitting and yelling), whereas girls use less overt forms of aggression such as negative gossip. Research on this matter showed that girls' aggressive tactics included gossip, ostracism, breaking confidences, and criticism of victim's clothing, appearance, or personality ${ }^{[4]}$. Girls rate such aggression as more hurtful than boys, suggesting their heightened sensitivity to it ${ }^{[3]}$.

This identification may be useful in developing reliable clinical tools to provide early detection and support to those young girls who are at risk of developing late onset of dysfunction in multiple areas. Several longitudinal studies show that adolescent girls with conduct disorder predictably suffered in multiple adult outcomes after adolescence.Their dysfunction unfolded over time and included poor physical health, high rates of psychiatric comorbidity, and participation in violent relationships ${ }^{[5]}$.Somestudies suggest that romantic involvement in adolescence decreases aggression in males and females, but decreases at a higher rate in females [6].

\section{Brain pathways}

Neuroanatomical models of brain circuitry involved in aggression and violence consistently implicate an interconnected network of regions that includes the frontal lobes and the amygdala along with other brain areas. Many of these models found dysfunction of the dorsolateral prefrontal cortex (DLPFC) creates a pathway to violence by way of executive dysfunction and consequent problems of meeting occupational/social/academic expectations ${ }^{[7,8]}$. Blair, using PET scans, assessed 13 male volunteers as they viewed static images of human faces expressing varying degrees of anger and found that increasing the intensity of angry facial expressions was associated with enhanced activity in participants' orbitofrontal cortex (OFC) and the anterior cingulate cortex $(\mathrm{ACC})^{[9]}$. Studies of aggressive, violent, and/or antisocial offenders using functional (SPECT and PET) and structural (MRI) neuroimaging are beginning to reveal abnormalities in these groups and review of these works reveals four consistent patterns: prefrontal dysfunction, temporal lobe dysfunction, particularly left sided medial-temporal (subcortical) activity, the relative balance of activity between the prefrontal cortex and the 
subcortical structures and the neural circuitry underlying the regulation of emotion and its affiliated behaviors.Also, recent neuroimaging research found that male youth with conduct disorder displayed reduced gray matter volumes in the left amygdala and anterior insula bilaterally compared to healthy controls and that these reductions were specifically related to aggressive behavior ${ }^{[10]}$

\section{Neurotransmitters}

A deficit in serotonin has been theorized to have a primary role in causing impulsivity and aggression.The hypothesized relationship between lowered CSF serotonin precursors and higher levels of aggression is supported by two longitudinal studies; however, there is not a simple inverse relationship ${ }^{[1]}$. Nevertheless, low levels of serotonin transmission may explain a vulnerability to impulsiveness, potential aggression, and may have an effect through interactions with other neurochemical systems. These include dopamine systems which are generally associated with attention and motivation toward rewards, and operate at various levels. Norepinephrine, also known as noradrenaline, may influence aggression responses both directly and indirectly through the hormonal system, the sympathetic nervous system or the central nervous system (including the brain). It appears to have different effects depending on the type of triggering stimulus, for example social isolation/rank versus shock/chemical agitation which appears not to have a linear relationship with aggression. Similarly, GABA, although associated with inhibitory functions at many CNS synapses, sometimes shows a positive correlation with aggression, including when potentiated by alcohol ${ }^{[12]}$.

\section{Hormones}

Testosterone

Gender differences in the rates of aggressive behaviors have naturally focused on the potential role of androgens, especially testosterone, in the development of violence. Numerous studies have found a correlation between higher levels of testosterone and physical aggression in boys ${ }^{[13]}$. In human studies, testosteroneaggression research has also focused on the role of the orbitofrontal cortex (OFC). This brain area is strongly associated with impulse control and self-regulation systems that integrate emotion, motivation, and cognition to guide context-appropriate behavior ${ }^{[14]}$.

\section{Cortisol}

Van Goozen in 2007claimed that there is a link between cortisol and aggression ${ }^{[15]}$. Cortisol is thought to lead toaggression because it is important in inhibiting other hormones which contribute to aggression. Mc Burnett in 2000 studiedand examined 38 boys aged 7-12 over a period of 4 years who had been referred to a clinic for problem behaviours. Boys with lower cortisol levels displayed $\mathrm{x} 3$ the number of aggressive symptoms and were consistently named as the most aggressive by their peers ${ }^{[16]}$. Hormones of the hypothalamic-pituitaryadrenal axis, involved in the stress response to threatening situations, also play an important and complex role in the regulation of aggression ${ }^{[17]}$.

\section{Genetics}

In a study in 1997,after assessing 182 monozygotic and 111 dizygotic male twin pairs, the researchers concluded that genetics could explain $40 \%$ of the total differences in aggression, whilst the environment could explain $50 \%$ of the differences in physical aggression, and $70 \%$ of the differences in verbal aggression ${ }^{[18]}$.Some studies have found a gender difference in the extent to which aggressive behaviour is inherited. For example, Button and his teamstudied 258 twin pairs aged 11-18, and found that the inheritance of antisocial aggressive behaviour was higher for females than males ${ }^{[19]}$. Retrospectively,Lundström et al., in 2013 found childhoodonset neuropsychiatric disorders to be common among violent offenders ${ }^{[20]}$.

\section{Social Cognitive Risk Factors}

\section{Social and Environmental Factors}

Lochman examined social cognitive variables in aggressive and nonaggressive boys at preadolescent and early adolescent developmental points ${ }^{[21]}$. They found that aggressive children often misread interpersonal cues and interpret ambiguous or pro social communication as hostile and react aggressively. The children also often have heightened sensitivity to rejection derived from early experiences of physical abuse or emotional neglect that then triggers anxiety or angry states ${ }^{[22]}$. Slaby and Guerra elaborated on the cognitive profile of these aggressive adolescents who believe that there are limited consequences for aggression, that aggression has concrete benefits, and that it is a legitimate response ${ }^{[23]}$. These findings are exceedingly important as understanding the impact of impaired social communication can assist families in understanding violent outbursts and serve as the basis for developing potential interventions. 


\section{Family Factors}

The family environment is the intimate system wherein development is shaped.Dishion et al developed a model of coercion that starts with family practices beginning in early childhood ${ }^{[24}$. In this typical scenario, when an oppositional child is aggressive, the parents fail to intervene early and to set reasonable standards for behavior. Thus, the child uses aggressive behavior to effectively terminate parental aversive requests, and in turn, the aggressive behavior is reinforced (escape conditioning). Consistent parental discipline, increased positive parental involvement, and increased monitoring of the child's activities were accompanied by significant reductions in a child's antisocial behavior. ${ }^{[25]} \mathrm{Also}$, recent research indicates that sibling aggression is related to the same serious mental health effects as peer bullying ${ }^{[26]}$.

\section{Role of Teacher}

A positive teacher-pupil relationship can moderate the associations between temperament and disruptive play, and with risky behaviour ${ }^{[27]}$. Children with developmental vulnerabilities have better educational outcomes when they receive strong emotional and instructional support in the classroom ${ }^{[28]}$. Conversely, unsupportive relationships may impair development and amplify psychosocial problems and psychological distress. There is evidence that problematic teacher-pupil relationships are stronger predictors of later school-related adjustment than positive relationships ${ }^{[29]}$.

\section{Peers and Gangs}

As with the development of other social behaviors, peers have an impact on aggression and violence in adolescence. Associating with delinquent peers was predictive of self-reported adolescent violence in several studies ${ }^{[30]}$. Unfortunately, in mixed groups of children, nonaggressive children are more likely to become aggressive than are aggressive children to become nonaggressive ${ }^{[31]}$.

Gangs may be a special case in peer relationships and violence. Numerous studies report an association between gang involvement and increased violence and delinquency ${ }^{[32,33]}$. The result of Thornberry's analysis of gang members supports a facilitation model where the norms and group processes of the gang exacerbate the behavior patterns of the individual gang members ${ }^{[34]}$.

\section{Culture, Environmental and Situational Factors}

Many scholars assert that culture is one factor that plays a role in aggression. Different rates of aggression or violence, currently or in the past, within or between groups, have been linked to the structuring of societies and environmental conditions influencing factors such as resource or property acquisition, land and subsistence techniques, and population change ${ }^{[35]}$.

Studies of communities and individuals confirm the popular impression that youth violence is more common in urban and impoverished neighbourhoods ${ }^{[36]}$. Certainly the impact of poverty on the family system contributes to the risk for violence and aggression, but the analysis of neighbourhood characteristics offers a more complex understanding. Collective efficacy shows that active engagement by adults to supervise and maintain order, neighbourhood residential stability, and concentrated affluence decreases the likelihood of violence in a community ${ }^{[37]}$. Another factor that adds to the vulnerability of the neighbourhood occurs when youth are exposed to violence, as this exposure increases the risk for aggressive behavior in youth ${ }^{[38]}$.Also, the relatively easy access to firearms for youth increases the risk of youth violence ${ }^{[39]}$.

A moderate relationship exists among illicit drug use, alcohol, and violence ${ }^{[40]}$. Alcohol can stir aggression by reducing threat-related inhibition and increasing arousability. Alcohol also decreases higher order cognitive functioning by altering the adolescent's ability to communicate and judge the degree of threat in a social situation ${ }^{[41]}$. Reduced cognitive control resulting from heavy alcohol consumption narrows perception and so can lead to an increased proneness to violent behavior in certain situations ${ }^{[42]}$. Aggression predicts substance use and substance use predicts aggression. Such understanding can provide the basis for a more tailored and individualized approach to developing prevention and intervention plans.

\section{Conclusion}

Numerous factors contribute to the relative risk for the development of violence and no single factor is associated with all aggression or provides absolute prediction. This review article provides specific information about some of the very early risk factors for violent behavior and has major policy implications and clinical relevance supporting intensive early intervention. Proper management and prevention can bring solution to many aggression and violent behaviour related problems. 


\section{References:}

[1]. Buss AH. The psychology of aggression. Hoboken,(1961); NJ: John WIley.

[2]. Beaver KM, Nedelec JL, Schwartz JA. Evolutionary behavioral genetics of violent crime :The evolution of violence, Springer, New York (2014); pp. 117-135

[3]. Galen BR,Underwood MK. A developmental investigation of social aggression among children. Developmental Psychology,(1997); 33, 589-600

[4]. Owens L, Shute R, Slee P. bI'm in and you're out. .Q: Explanations for teenage girls' indirect aggression. Psychology, Evolution, and Gender,(2000b); 2, 19-46.

[5]. Pajer KA. What happens to "bad" girls? A review of the adult outcomes of antisocial adolescent girls. Am J Psychiatry 1998;155:862-70

[6]. Xie H. "Developmental trajectories of aggression from late childhood through adolescence: similarities and differences across gender"Aggressive Behavior(2011)37 (5): 387-404

[7]. Blair RJ. Neurocognitive models of aggression, the antisocial personality disorders, and psychopathy. Journal of Neurology, Neurosurgery and Psychiatry,2001; 71, 727-731

[8]. Giancola, PR, Evidence for dorsolateral and orbital prefrontal cortical involvement in the expression of aggressive behavior. Aggressive Behavior.1995, 21, 431-450.

[9]. Blair, K. S., Newman, C., Mitchell, D. G. V., Richell, R. A., Leonard, A., Morton, J., et al ..Differentiating among prefrontal substrates in psychopathy: neuropsychological test fi ndings. Neuropsychology,(2006);20 (2), 153-165

[10]. Sterzer, P., Stadler, C., Poustka, F., Kleinschmidt, A. A structural neural deficit in adolescents with conduct disorder and its association with lack of empathy. Neuroimage 37,2007; 335-42.

[11]. Clarke RA, Murphy DL, Constantino JN. Serotonin and externalizing behavior in young children. Psychiatry Res 1999;86:29-40

[12]. Pihl, RO \&Benkelfat, C. 'Neuromodulators in the Development and Expression of Inhibition and Aggression' in Developmental Origins of Aggression, 2005. The Guilford Press.

[13]. Scerebo A, Kolko D. Salivary testosterone and cortisol in disruptive children: Relationship to aggressive, hyperactive, and internalizing behaviors. J Am Acad Child Adolesc Psychiatry 1994;33:1174-84.

[14]. Mehta, P. H., Beer, J. (2009). "Neural mechanisms of the testosterone-aggression relation: the role of orbitofrontal cortex. Journal of Cognitive Neuroscience". J CognNeurosci22 (10): 2357-2368

[15]. Van Goozen, S.H.M., Fairchild, G., Snoek, H., \& Harold, G.T. (2007). The evidence for a neurobiological model of childhood antisocial behaviour. Psychological Bulletin, 133, 149-182

[16]. McBurnett, K., Lahey, B.B., Rathouz, P.J., and Loeber, R. Low salivary cortisol and persistent aggression in boys referred for disruptive behavior. Arch Gen Psychiatry. 2000; 57: 38-43

[17]. D.H. Barzman, A. Patel, L. Sonnier, J.R. Strawn. Neuroendocrine aspects of pediatric aggression: Can hormone measures be clinically useful? Neuropsychiatric Disease and Treatment, 11 (2010), pp. 691-697

[18]. Coccaro EF, Bergeman CS, McClearn GE (1993): Heritability of irritable impulsiveness: A study of twins reared together and apart. Psychiatry Res 48:229-242

[19]. Button TMM, Scourfield J, Martin N, McGuffin P. Do aggressive and non-aggressive antisocial behaviors in adolescents result from the same genetic and environmental effects? Am J Med Genet B Neuropsychiatr Genet. 2004;129 B:59-63

[20]. S. Lundström, M. Forsman, H. Larsson, N. Kerekes, E. Serlachius, N. LångströmChildhood neurodevelopmental disorders and violent criminality: A sibling control study Journal of Autism and Developmental Disorders (2013), pp. 1-10

[21]. Lochman JE, Coie JD, Underwood M, et al. Effectiveness of a social relations intervention program for aggressive and non-aggressive, rejected children. J Consult ClinPsychol 1993;61:1053-8

[22]. Dodge KA, Bates J, Pettit GS. Mechanisms in the cycle of violence. Science 1990;250:1678-83

[23]. Slaby RG, Guerra NG. Cognitive mediators of aggression in adolescent offenders. Dev Psychol 1988;24:580-8

[24]. Dishion TJ, Patterson GR, Kavanagh KA. An experiential test of the coercion model: Linking theory, measurement, and intervention. In: McCord J, Tremblay RE (eds). Preventing Antisocial Behavior: Interventions from Birth Through Adolescence. New York, NY: Guilford Press, 1992:253-82

[25]. Farrington DP. The family backgrounds of aggressive youths. In: Hersov LA, Berger M, Shaffer D (eds). Aggression and Antisocial Behavior in Childhood and Adolescence. Oxford, UK: Pergamon Press, 1978:73-93

[26]. Corinna Jenkins Tucker, David Finkelhor, Heather Turner, and Anne Shattuck. Association of sibling Aggression with Child and Adolescent Mental Health, Pediatrics, June 17, 2013

[27]. Rudasill KM, Reio TG, Stipanovic N, Taylor JE. A longitudinal study of studentteacher relationship quality, difficult temperament and risky behaviour from childhood to early adolescence. J SchPsychol 2010; 48: 389-412

[28]. Hamre BK, Pianta RC. Can instructional and emotional support in the first grade classroom make a difference for children at risk of school failure? Child Dev 2005; 76: 949-67

[29]. Ladd GW, Birch SH, Buhs ES. Children's social and scholastic lives in kindergarten: related spheres of influence? Child Dev 1999; 70: $1373-400$

[30]. Farrington DP. Early predictors of adolescent aggression and adult violence. Violence Vict 1989;4:79-100

[31]. Snyder H, Finnegan T, Stahl A, et al. Easy Access to Juvenile Court Statistics: 1986-1995. Pittsburgh, PA: National Center for Juvenile Justice, 1997.

[32]. Thomas C, Holzer C, Wall J. Serious delinquency and gang membership. Adolesc Psychiatry 2003;27:61-81.

[33]. Battin S, Hill K, Abbott R, et al. The contribution of gang membership to delinquency beyond delinquent friends. Criminology 1998;36:93115 .

[34]. Thornberry TP. Membership in youth gangs and involvement in serious violent offending. In: Loeber R, Farrington DP, (eds.), Serious and Violent Juvenile Offenders: Risk Factors and Successful Interventions. Thousand Oaks, CA: Sage Publications, 1998:147-66.

[35]. Lomas, W. (2009) Conflict, Violence, and Conflict Resolution in Hunting and Gathering Societies Totem: The University of Western Ontario Journal of Anthropology, Volume 17, Issue 1, Article 13

[36]. Hawkins JD, Herronkohl T, Farrington DP, et al. A review of predictors of youth violence. In: Loeber R, Farrington DP (eds). Serious and Violent Juvenile Offenders: Risk Factors and Successful Interventions. Thousand Oaks, CA: Sage Publications, 1998:106-47

[37]. Brewer DD, Hawkins JD, Catalano RF, et al. Preventing serious, violent, and chronic juvenile offending: A review of evaluations of selected strategies in childhood, adolescence, and the community. In: Howell JC, Krisberg B, Hawkins JD, et al (eds). Sourcebook on Serious, Violent, and Chronic October 2004 AGGRESSION AND VIOLENCE IN YOUTH 273 Juvenile Offenders. Thousand Oaks, CA: Sage Publications, 1995:271-6

[38]. Sampson RJ, Raudenbush SW, Earls F. Neighborhoods and violent crime: A multilevel study of collective efficacy. Science 1997;277:91824

[39]. Ash P, Kellermann AL, Fuqua-Whitley D, Johnson A. Gun acquisition and use by juvenile offenders. JAMA 1996;275: 1754-8.

[40]. Volavka J. Violence and Psychoactive Substance Abuse in Neurobiology of Violence, 2nd edition. Washington, DC: APPI, 2002, 197-218

[41]. Bell C, Gamm S, Ballas P, et al. Strategies for the prevention of youth violence in Chicago public schools. In: Saffi M, Saffi SL (eds). School Violence: Assessment, Management, Prevention. Washington, DC: American Psychiatric Press, 2001:251- 72

[42]. Beck, A; Heinz, A. Alcohol-Related Aggression: Social and Neurobiological Factors. DeutschesÄrzteblatt International, November 2013 